\title{
Performance evaluation of concentric screen grader
}

\section{S.G. PAWAR, M.S. PAWAR AND S.U. KHODKE}

Received : 25.07.2014; Revised : 19.03.2015; Accepted : 30.03.2015

See end of the Paper for authors' affiliation

Correspondence to :

\section{S.G. PAWAR}

Depatment of Agricultural Process Engineering, Dr. Panjabrao Deshmukh Krishi Vidhyapith, AKOLA (M.S.) INDIA

Email : savitapawar100@gmail.com
-ABSTRACT : The machine main frame had dimensions $2000 \mathrm{~mm} \times 1250 \mathrm{~mm} \times 1000 \mathrm{~mm}$, with a approximate cost of Rs. 45,000. The performance parameters such as actual capacity, grading efficiency of each grade, overall grading efficiency, damage loss and peel loss were studied in this work. The operating speed of the grader was maintained at constant speed 16 revolutions. The maximum grading efficiency of 96 and 62.3 per cent was found in onion and potato grading, respectively. The cost of the mechanical grading obtained was Rs. 30 per tonne. The ratio of cost for manual to mechanical grading worked out to be 12.45:1. During the performance test only peel loss was observed in onion grading while in case of potato grading more damage occurred. Therefore, this grading is only suitable for onion grading.

- KEY WORDS : Fruit-vegetable grader, Screen grader, Onion, Potato

口 HOW TO CITE THIS PAPER : Pawar, S.G., Pawar, M.S. and Khodke, S.U. (2015). Performance evaluation of concentric screen grader. Internat. J. Agric. Engg., 8(1) : 140-143. 